Article

\title{
Fatigue Performance of Mg-Zn-Zr Alloy Processed by Hot Severe Plastic Deformation
}

\author{
Evgeni Vasilev ${ }^{1}$, Mikhail Linderov ${ }^{1}$, Dayan Nugmanov ${ }^{2}$, Oleg Sitdikov ${ }^{2}$, \\ Mikhail Markushev ${ }^{2}$ and Alexei Vinogradov ${ }^{1, *}$
}

1 Institute of Advanced Technologies, Togliatti State University, Togliatti 445667, Russia;

E-Mails: evg.vasilyev11@gmail.com (E.V.); dartvi@gmail.com (M.L.)

2 Institute for Metals Superplasticity Problems, Russian Academy of Science, Ufa 450001, Russia;

E-Mails: dn86@list.ru (D.N.); sitdikov@nm.ru (O.S.); mvmark@imsp.ru (M.M.)

* Author to whom correspondence should be addressed; E-Mail: alexei.vino@ gmail.com;

Tel.: +7-8482-546-303; Fax: +7-8482-546-444.

Academic Editor: Hugo F. Lopez

Received: 9 November 2015 / Accepted: 4 December 2015 / Published: 8 December 2015

\begin{abstract}
Fatigue properties under axisymmetric push-pull loading of a magnesium alloy Mg-6Zn-0.5Zr (ZK60) after processing by multiaxial isothermal forging (MIF) to a total strain of 4.2 at $400{ }^{\circ} \mathrm{C}$ were investigated. The strong influence of the microstructure on the mechanical behavior is demonstrated. Hot severe plastic deformation was shown effective in improving the fatigue life in both the high- and low-cyclic regimes.
\end{abstract}

Keywords: magnesium alloys; severe plastic deformation; fatigue properties

\section{Introduction}

Having a low density, outstanding specific strength, and high damping capacity and recyclability, magnesium alloys are attractive for weight-sensitive applications in load-bearing components in the automotive and airspace industries. Good fatigue performance is obviously one of the most important requirements from this perspective. A thorough survey of the experimental data available to date on the fatigue properties of $\mathrm{Mg}$ alloys has been reported by Xiong and Jiang [1]. It was noticed that, while the effect of loading conditions such as strain/stress amplitude, strain/stress ratio, loading rate and mean stress have been studied in considerable detail, the effect of microstructural factors such as grain 
structure, texture, and second phases, on both the low- and high-cycle fatigue (LCF and HCF) behavior of $\mathrm{Mg}$ alloys is far from being understood. The problems arise in view of the complexity of deformation mechanisms operating and interacting simultaneously with each other in $\mathrm{Mg}$-based systems. Although the fatigue behavior of $\mathrm{Mg}$ alloys apparently depends on these factors, the improvement of fatigue properties through microstructure control is tricky because, among the above-listed ones, it is hard to identify those which have most influence on the fatigue behavior. For example, the authors of [2] hardly identify the governing structure parameter(s) of the fatigue life of the as-extruded AZ31 Mg alloy, which is only slightly longer than that of its annealed counterpart at identical strain amplitudes. Moreover, usually processing via rolling or pressing results in a strong crystallographic texture where the $c$-axis of the majority of the grains is perpendicular to the longitudinal axis of the product. The strong texture leads to a strong tension-compression asymmetry in deformation [3-7] and is detrimental for fatigue performance.

Over the recent years, severe plastic deformation (SPD) techniques have gained popularity as an efficient vehicle for modifying the microstructure and the strengthening of metallic materials by grain refinement [8]. Besides, the texture in $\mathrm{Mg}$ alloys can be considerably changed by SPD, in particular in the course of simple shear processing via equal channel angular pressing (ECAP) [9-11]. It was demonstrated that the ductility of Mg alloys (AZ31 as an example) after ECAP can be significantly improved without considerable grain refinement by texture modification [9]. Zuberova et al. [12] found that it was difficult to rationalize the relation between the grain size, the ultimate tensile strength, and the fatigue resistance in the case of hot-rolled and equal-channel angular pressed AZ31. On the other hand, Vinogradov et al. [13] have demonstrated that integrated SPD processing involving direct extrusion combined with two ECAP passes resulting in the total equivalent strain of 5.4 is effective for improving the HCF performance of the ZK60 alloy: the HCF endurance limit in axisymmetric push-pull fatigue testing reached $160 \mathrm{MPa}$, which is very high value for this class of alloys. A variety of sophisticated SPD techniques have been developed [12,14-17] with the aim of improving the mechanical properties including fatigue [18-21]. Among them, multiaxial isothermal forging (MIF) has long been recognized as a cost-effective and industrially scalable SPD technique. Unfortunately, the fatigue behavior of MIF-processed Mg alloys has not been investigated to date.

To get better insight into the fatigue behavior of $\mathrm{Mg}$ alloys, the present study was aimed at (i) investigating both the low- and high-cycle fatigue properties of the alloy ZK60 with and without SPD processing by MIF, and (ii) relating this behavior to the microstructure.

\section{Experimental Procedure}

\subsection{Materials and Preparation}

The billets of the alloy ZK60 (nominal composition $\mathrm{Mg}-6 \mathrm{Zn}-0.5 \mathrm{Zr}$, in wt.\%) with dimensions $70 \times 70 \times 170 \mathrm{~mm}^{3}$ were MIF-processed at $400{ }^{\circ} \mathrm{C}$ from a hot-pressed 90-mm-diameter rod in T6 condition. A hydraulic press equipped with an isothermal die set was used for MIF processing. During processing, the billet experienced six deformation cycles involving a sequence of settings and drawings with axis changing in accordance to the strain path illustrated in Figure 1 (see [22] for details). The total true strain imparted on a working billet was of 4.2 and the last deformation cycle 
was ended by oil cooling. The coarse grain cast alloy ZK60 was used as a reference material (for more details of processing, structure and properties, see ref. [16]).
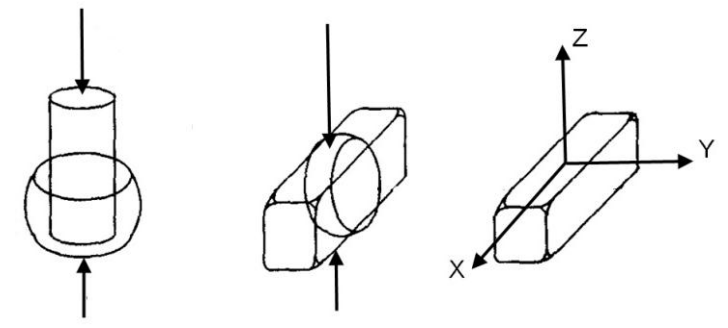

Figure 1. Schematic illustration of the strain path and axis designation under MIF.

\subsection{Microstructure Characterization}

The alloy structure was analyzed in the longitudinal plane $(X-Z)$ of the billets in the field emission gun scanning electron microscope (SEM) Zeiss Sigma (Jena, Germany) equipped with the high-sensitivity Hikari electron back scattering diffraction (EBSD), (EDAX/TSL, Mahwah, NJ, USA) camera and orientation image microscopy (OIM-6.2, EDAX/TSL, Mahwah, NJ, USA) software package. Prior to mechanical testing or microstructural analysis, the samples were mechanically polished to a mirror-like finish and then electrolytically polished in $90 \%$ isopropyl alcohol $+10 \%$ nitric acid solution.

\subsection{Mechanical Testing}

The specimens for mechanical testing were cut by spark erosion in the longitudinal direction of the working billets, i.e., along $[X]$ axis of the MIF-processed billets, $c f$. Figure 1 . The uniaxial tensile tests were performed using the conventional I-shaped specimens with the gauge length of $10 \mathrm{~mm}$ on the screw-driven testing machine (Kammrath \& Weiss, Dortmund, Germany) under constant crosshead velocity corresponding to a nominal strain rate of $1 \times 10^{-4} \mathrm{~s}^{-1}$. For the fatigue test, the sub-size specimens with cross-section of $2 \times 2 \mathrm{~mm}^{2}$ and a gauge length of $5 \mathrm{~mm}$ were used. All specimens for mechanical testing were mechanically polished to a mirror-like surface finish. An Instron Electropuls 1000 electro-mechanical testing machine operating in a symmetric push-pull cycling $(R=-1)$ mode was used for the tests at ambient temperature in dry air. For the HCF, the tests were performed in the stress control regime at constant stress amplitude $\Delta \sigma / 2$ at $10 \mathrm{~Hz}$ frequency, while for the LCF the total strain control mode at $0.2 \mathrm{~Hz}$ frequency was implemented using a dynamic clip-on extensometer with $5 \mathrm{~mm}$ inter-probe distance.

\section{Experimental Results and Discussion}

The typical SEM images in back-scattered electron (BSE) contrast and the EBSD maps for the as-cast (reference) and MIF-processed alloys, as well as the corresponding grain size distributions (with edge grains excluded), are shown in Figure 2. After homogenization, the cast alloy is characterized by a coarse-grain $\alpha-\mathrm{Mg}$ matrix with near-equilibrium $\mathrm{Mg}-\mathrm{Zn}$ eutectic structures decorating grain boundaries and triple junctions, as illustrated in Figure 2a. The microstructure after 
MIF consisted of nearly uniform, fine, equiaxed grains with a volume fraction of $75 \%-80 \%$. Thus, the fine grains can be regarded as the main structural component after MIF. Besides, the equiaxed or slightly elongated fragments of the original grains with dimensions of tens of microns were also observed as a result of incomplete recrystallization (not shown in Figure 2). Nevertheless, Figure 2 shows that most of the grains in the both structural states appeared to be nearly equiaxed on the investigated planes. Their size was found to be log-normally distributed with the mean values of 73 and $5 \mu \mathrm{m}$ for the reference and the MIF-treated specimens, respectively, as shown in Figure 2e,f. Thus, the considerable grain refinement after SPD is clearly seen in line with common expectations. Besides, it has been found that the non-uniform distribution of $\mathrm{Mg}-\mathrm{Zn}$ excess phases and precipitates is retained in the present alloy, even after hot MIF [23]. Some strings of excess phases aligned in the shearing direction in MIF, i.e., at the angle of $\sim 30^{\circ}-45^{\circ}$ to the billet's $[X]$-axis, were seen in SEM images and optical micrographs.
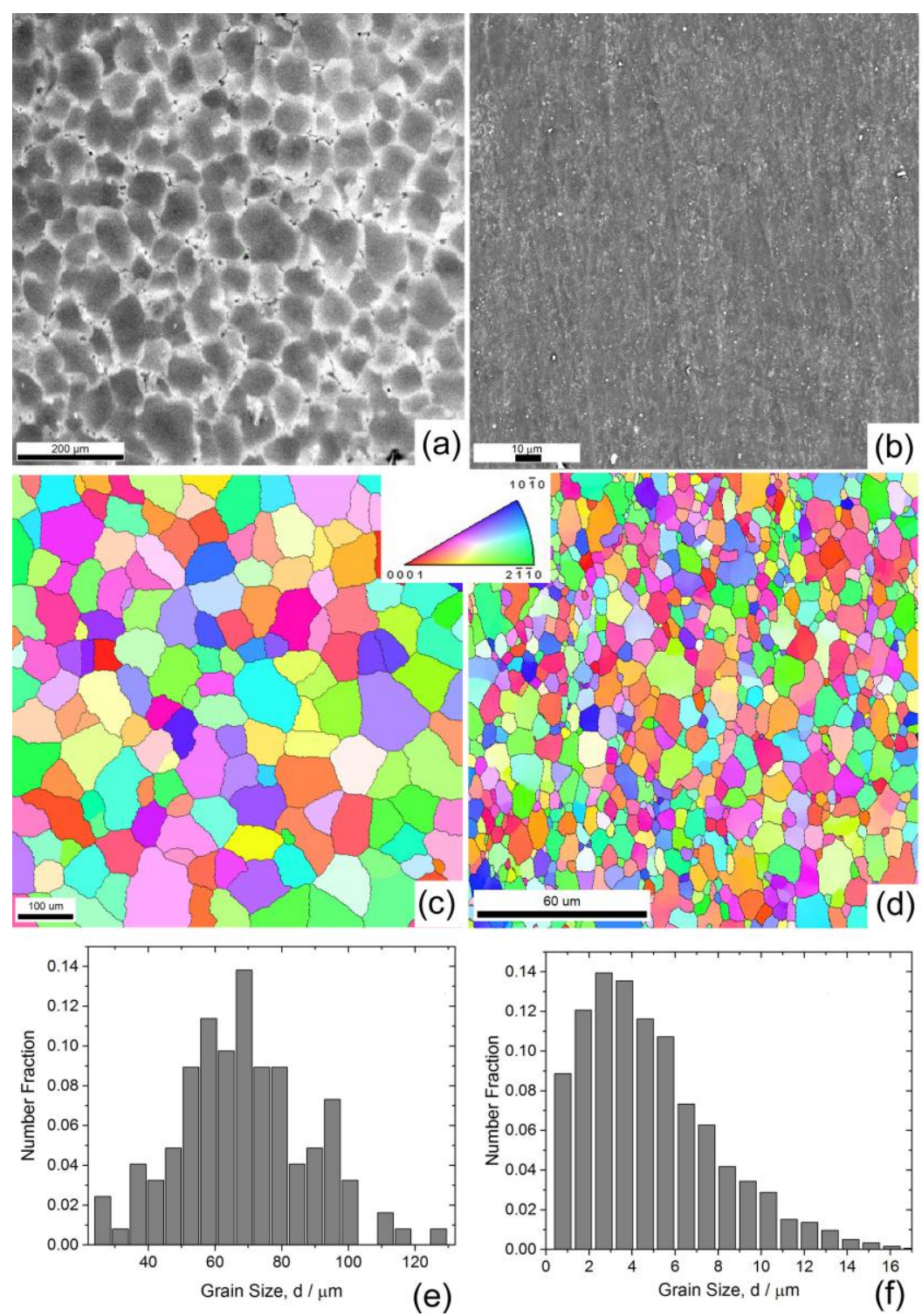

(b)
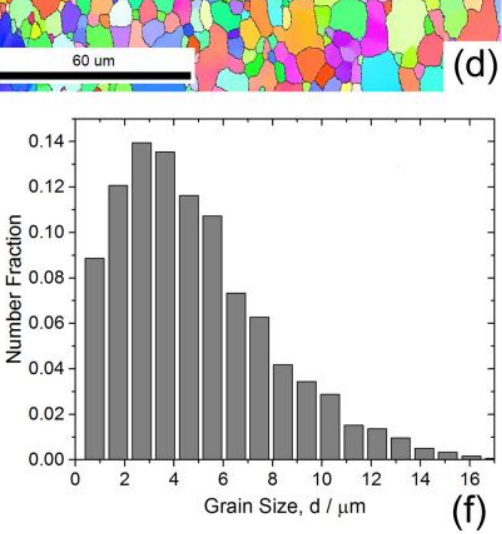

Figure 2. Back-scattered electron images (a,b) and OIM EBSD maps (c,d) and corresponding grain size distributions $(\mathbf{e , f})$ for the coarse-grain as-cast $(\mathbf{a}, \mathbf{c}, \mathbf{e})$ and fine-grain MIF-processed (b,d,f) ZK60 alloy in the $(X-Z)$ plane. 
Figure 3 illustrates that the materials performance under monotonic loading is improved considerably due to microstructure modification by MIF. For SPD-processed materials, the common increase in strength is accompanied by a significant increase in ductility: the elongation to failure increased almost by a factor of four up to $40 \%$. With a simultaneous increase in yield and ultimate tensile strength up to values typical to those of conventional wrought and heat-hardened alloys, this yields a novel remarkable balance of properties. The effect is generally associated with hot SPD conditions resulting in a uniform fine-grain structure of the alloy. However, fine grain size alone cannot account for the substantial change in properties observed in the present work. In the complex ZK60 alloy the crystallographic texture, size, and distribution of primary and secondary phases also play an important, if not a key, role in the overall mechanical response and, thus, the cumulative effect of solution strengthening and precipitation strengthening may supersede the effect of grain size or texture. The separation of effects from different influencing factors on fatigue is always a challenging task. In the present investigation we emphasize the role of grain size, which has been most obviously changed by SPD processing. The role of other important factors - texture and distribution of secondary phases - will be discussed only briefly and will be covered in further dedicated publications in detail.

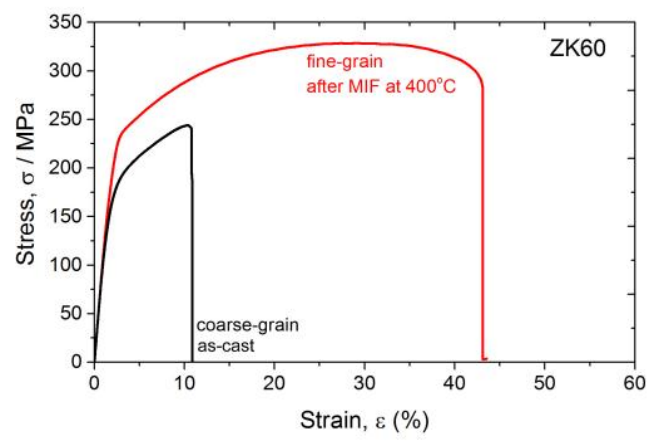

Figure 3. Monotonic tensile stress-strain curves for the reference coarse grain and MIF-processed fine-grain ZK60 alloy.

A traditional fatigue improvement strategy is based on the following couple of empiric correlations: (i) the higher the strength under monotonic loading, the higher the endurance (fatigue) limit in HCF is and (ii) the higher the monotonic ductility, the longer the fatigue life in LCF is [24] (see also reviews [19,25] specific for ultrafine-grained metals). As was mentioned above, following this strategy, SPD through combined extrusion and ECAP processing gave rise to a remarkable improvement of the fatigue limit in the HCF regime in the ZK60 alloy [13]. Wu et al. [26] have demonstrated for the AZ31B alloy that the LCF life resulting from combining the effects of grain refinement and texture can be enhanced through ECAP. Unfortunately, no discussion on LCF properties has been extended in [13] whereas no data on the HCF properties have been reported in [26]. The enhancement of both strength and ductility of the MIF-processed Mg alloy, shown in Figure 1, is promising for promoting improvement of the fatigue properties in both LCF and HCF regimes.

Typical examples of the stabilized cyclic hysteresis loops obtained at two total strain amplitude ranges, $\Delta \varepsilon_{t}=2 \%$ and $0.8 \%$, which correspond to the largest and medium strain amplitudes used in the LCF tests, are shown in Figure 4. 

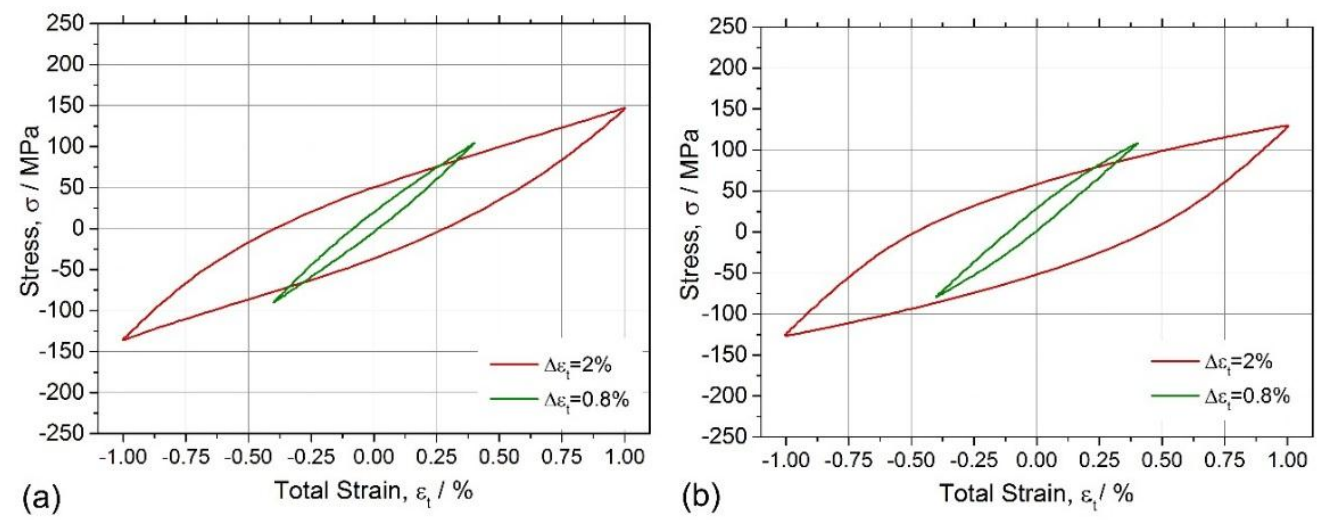

Figure 4. Typical examples of the stabilized cyclic hysteresis loops obtained at two total strain amplitude ranges, $\Delta \varepsilon_{t}=2 \%$ and $0.8 \%$, for the coarse-grain reference (a) and fine-grain MIF-processed (b) ZK60 alloy.

For materials where plastic deformation is mediated by dislocation slip, the stabilized stress-strain hysteresis loops are symmetrical and similar to each other. The picture is quite different in $\mathrm{Mg}$ alloys due to the tension-compression asymmetry caused by profuse twinning in favorably oriented grains. The effect is particularly significant in strongly textured materials, e.g. those after extrusion, $c f$. [3,27]. For the Mg alloy ZK60, Yu et al. [28] demonstrated in uniaxial strain-control experiments that the asymmetry of the hysteresis loop is pronounced only at fairly high strain amplitudes exceeding $5.2 \times 10^{-3}$, and diminishes at strain amplitudes below $4.5 \times 10^{-3}$. A very similar conclusion was drawn by Begum et al. [4] for the extruded AZ31 alloy. Though the same trend is observed in the present study for the ZK60 alloy in both microstructural states, as seen in Figure 4, the asymmetry of the cyclic hysteresis loops is not as pronounced as in strongly textured alloys. The main reason for that is apparently related to the texture which is much weaker in both studied alloy conditions than that in the conventional extruded Mg alloys. Notwithstanding, the effect of texture and the interplay between the dislocation slip and twinning cannot be completely eliminated even in weakly textured Mg alloys [29]. As a result, some tensile mean stress arises in both alloy types. However, in the fine-grain alloy it is slightly higher than in the coarse-grain one. The mean stress is regularly observed in $\mathrm{Mg}$ alloys during the strain-controlled fatigue test [1-3], which is supposed to be produced by a combined effect of cyclic hardening in tension and easy yielding in compression [3] caused by the polar nature of twinning. Mechanical twinning is also a root cause of the concavity of the hysteresis loop, which is noticeable in Figure 4 for both alloy conditions tested at a larger strain amplitude. Not surprisingly, the concavity is more distinct in the coarse-grain specimen which exhibits more profuse twinning than in its fine-grain counterpart, $c f$. also [30]. The mean stress inevitably exerts an appreciable effect on the overall fatigue life [28] and the role of the mean stress has been well highlighted in the cited literature. Therefore, details of this effect are beyond the scope of the present work, although the nature of the mean stresses after SPD has yet to be understood in the intimate connection with fine details of texture.

The LCF and HCF regimes are conventionally distinguished on the basis of the applied strain amplitude. The fatigue life in these regimes is characterized commonly in terms of the $\varepsilon-\mathrm{N}$ fatigue life curves, where the number of strain reversals to failure $2 \mathrm{~N}_{\mathrm{f}}$ is represented as a function of the total (or 
plastic) strain amplitude $\Delta \varepsilon t / 2$ and the $\sigma-\mathrm{N}$ curves (known also as the Wöhler plot), as shown in Figure 5a,b, respectively.

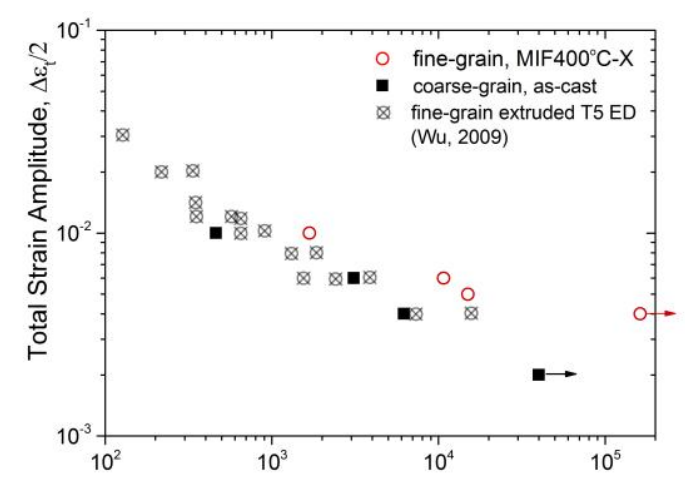

(a)

Number of Reversals to Failure, $2 \mathrm{~N}_{\mathrm{f}}$

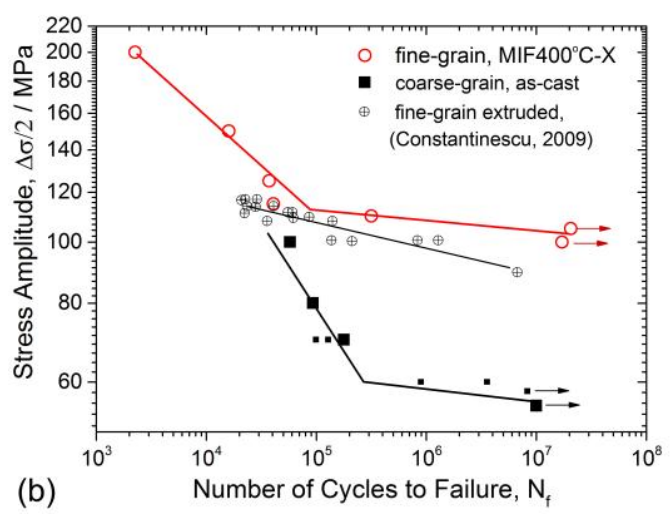

Figure 5. LCF diagram plotted in terms of $\varepsilon-\mathrm{N}$ curves (a) and the $\sigma-\mathrm{N}$ curve (b) for the coarse-grain as-cast and fine-grain extruded and MIF-processed ZK60 alloy (conditions). Large black rectangles on (b) correspond to experiments performed on round-shaped 3-mm-diameter specimens [13], small rectangles correspond to experiments performed on rectangular specimens with a $2 \times 2 \mathrm{~mm}^{2}$ cross-section (present work). Data derived from the literature [31,32] for the commercial ZK60 extruded alloys tested under similar conditions are plotted for comparison.

Figure 5 shows that, in line with common trends, the SPD processing by hot MIF exerted a dramatic effect on the fatigue performance if compared to the coarse-grained counterpart. The effect is more modest if the commercially processed materials are chosen for comparison. Notwithstanding, one can notice an appreciable positive influence of MIF on both LCF and HCF properties. In both regimes the positive effect is more pronounced at lower strain amplitudes.

Most ultrafine-grained metals and alloys produced by SPD techniques exhibit the same trend in the $\mathrm{HCF}$ regime: their fatigue strength is considerably higher than for coarse-grain material. More troublesome are usually the LCF results: regardless of the SPD technique used to produce ultrafine-grain metals, they are consistently inferior in their ability to sustain cyclic loads in the LCF regime. However, the $\mathrm{Mg}$ alloys appear to be outside of this mainstream. The inferior LCF performance of ultrafine-grain metals can be rationalized in terms of their commonly poor ductility after SPD [14,33], while, as has been shown above, the ductility and the LCF properties can improve concurrently with strength in Mg alloys after SPD. While the increase in strength and HCF properties can be attributed to grain refinement and Hall-Petch-type strengthening in the fine-grain materials, the improvement in ductility is hard to rationalize without considering the effect of texture. Texture evolution during MIF was the subject of a recent investigation [34]. It was shown that the sharp initial fiber texture tends to spread and weaken after MIF (readers are encouraged to review ref. [34] for detailed coverage), favoring non-basal dislocation slip. Thus, enhancement of ductility can be attributed to the alternation of the underlying deformation mechanisms with grain refinement by SPD: twinning, which is profuse in the coarse-grain $\mathrm{Mg}$ alloys, is impeded with grain refinement, thus facilitating dislocation slip in non-basal systems. 

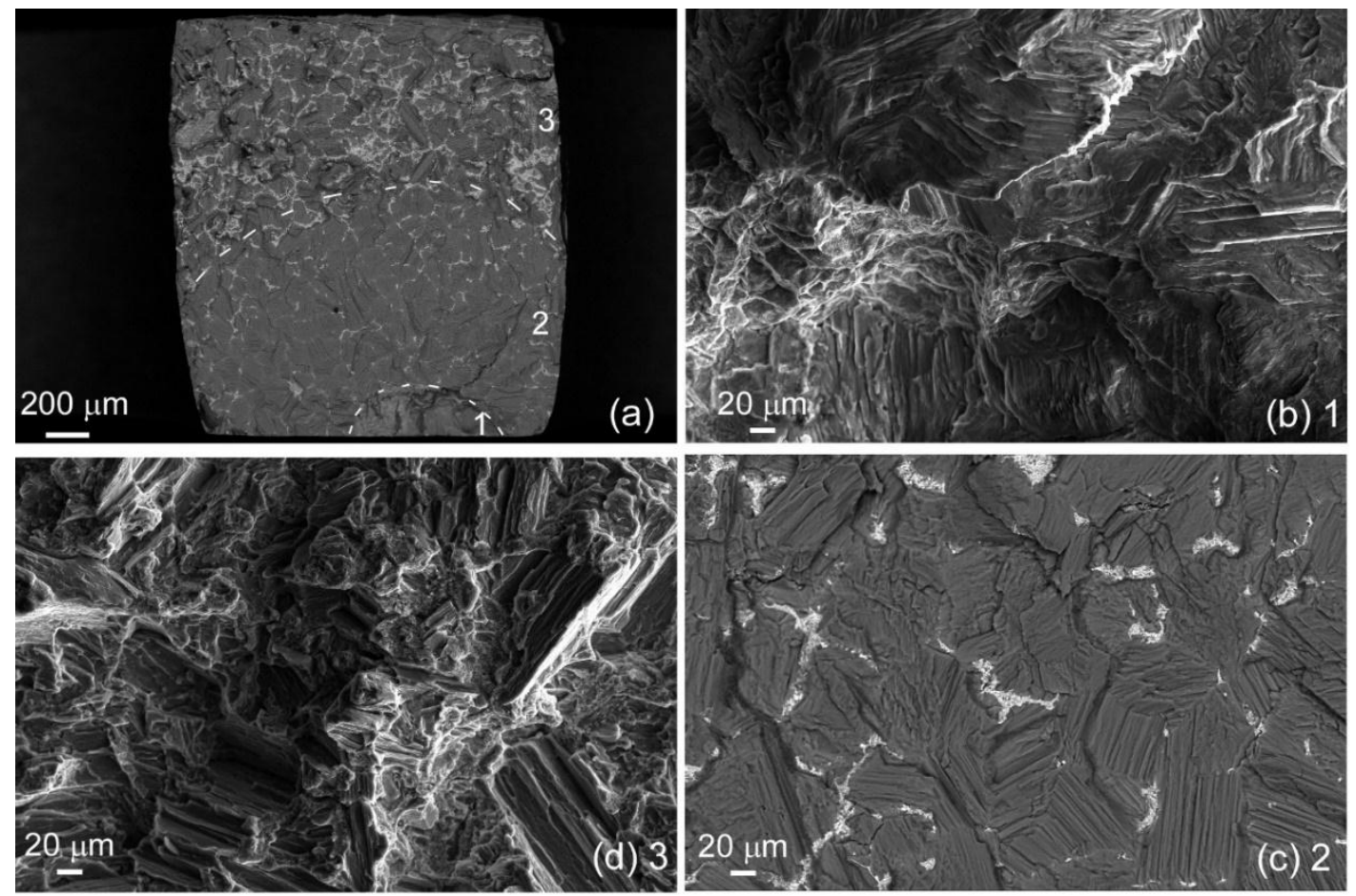

Figure 6. Fatigue fractures of as-cast ZK60 alloy after LCF at $0.4 \%$ total strain amplitude. (a) general view of the fracture surface, (b), (c) and (d) enlarged fragments of the same surface representing typical topological details of the fatigue crack initiation region 1 , stable crack propagation region 2 and rupture region 3 , respectively.
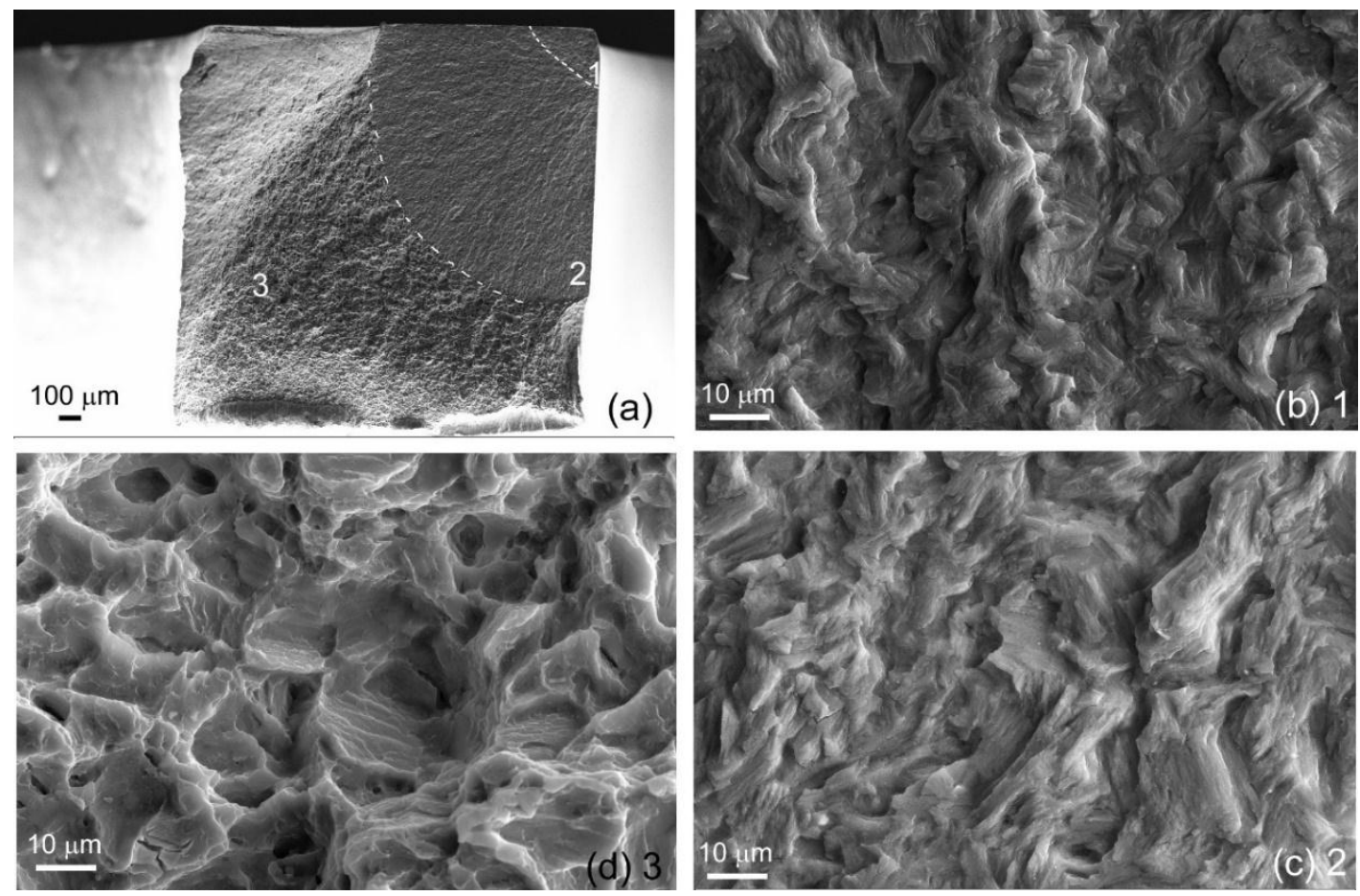

Figure 7. Fatigue fractures of MIF-processed ZK60 alloy after LCF at $0.5 \%$ total strain amplitude. (a) general view of the fracture surface, (b), (c) and (d) enlarged fragments of the same surface representing typical topological details of the fatigue crack initiation region 1, stable crack propagation region 2 and rupture region 3 , respectively. 
Figures 6 and 7 represent the SEM overviews of fracture surfaces in secondary and back-scattered electrons of the reference as-cast and MIF-processed samples, respectively, after LCF. Three characteristic regions of fatigue fracture can be identified on the micrographs. These regions are typical of fatigue fracture and include the zone of fatigue crack initiation (Region 1) followed by the area of steady crack propagation (Region 2), and the final rupture (Region 3). As a result of surface roughening caused by dislocation slip during cyclic deformation, the fatigue cracks initiate at the surface nearly normally to the loading axis. A close-up of the fracture surface near the crack nucleation area shows a sort of cleavage feature, which consists of numerous lamellar cleavage planes, as shown in Figures $6 \mathrm{~b}$ and $7 \mathrm{~b}$. The striation-like features can hardly be seen on the fracture surface while the secondary microcracks along the cleavage plane are commonly observed on Regions 1 and 2 in Figures 6 and 7. The fracture topology of the tearing region (Region 3) suggests that the unstable fatigue crack propagates by coalescence of dimples in a ductile manner.

BSE-SEM observations and EDS results reveal a network of intermetallic Mg-Zn particles having a very bright contrast on a fatigue fracture surface of the reference specimen, as shown in Figure 6b,c, Regions 1 and 2. No such network can be identified in the processed sample, shown in Figure 7. Its fracture surface has a much more developed topography on a microscopic scale. Indeed, the fracture surface relief in Regions 1 and 2 is strikingly different in both specimens. Similar to Region 1, the zone of stable crack propagation, Region 2, is rather planar on a large scale in both specimens. This region exhibits a rather fine and homogeneous pattern with brittle cleavage facets which are much more clearly visible in the reference specimen. However, it has more developed coarse local variations in its relief in the MIF-processed fine-grain specimen, $c f$. Figures $6 \mathrm{c}$ and 7c. Apparently, the signatures of mechanical twinning are dominant on the fracture surface of the coarse-grain reference specimen in both Regions 1 and 2. Fine twin lamellae are also visible (though admittedly less pronounced) at the crack initiation site of the fine-grain MIF-processed specimen. However, no such features were observed at the stage of stable crack growth, as seen in Figure 7c. In combination with the above-highlighted difference in the distribution of secondary phases, this indicates ductile fracture in the processed sample as opposed to fairly brittle fracture in the initial one. The appearance of the rupture surface is also different, and it stems from the difference in the grain size of the reference and processed specimens. With regard to the difference in the underlying fatigue mechanisms, the better-developed surface in the MIF-processed fine-grain specimen dominated by terrace-like morphology reflecting dislocation slip is evidence of a more tortuous crack path, resulting in greater crack closure and higher energy dissipation in the processed material than in its coarse-grain counterpart exhibiting profuse twinning. Such behavior is indicative of the improved resistance of the fine-grain alloy ZK60 to fatigue crack propagation after MIF processing.

Overall, it can thus be stated that the alloy ZK60, processed by severe plastic deformation via multiaxial isothermal forging, possesses a promising combination of tensile and fatigue properties. Finally, let us notice that the improvement of corrosion resistance in the fine-grain state after MIF has also been documented and the respective results will be reported elsewhere. 


\section{Conclusions}

In summary, the fatigue performance of magnesium alloy ZK60 fine-grained during multiaxial isothermal forging up to the effective strain of 4.2 at $400{ }^{\circ} \mathrm{C}$ has been evaluated. It has been shown that such processing remarkably improves both the HCF endurance limit and the LCF life in axisymmetric push-pull fatigue testing if compared not only with its as-cast coarse-grain counterpart, but also with the commercially extruded alloys. The observed enhancement of fatigue properties is related to the increase of ductility and ultimate tensile strength as a result of microstructure modification by hot severe plastic deformation. However, the full potential of achieving favorable combinations of grain refinement, texture, and distribution of primary and secondary phases has certainly not been explored to a full extent. A better understanding of the specific mechanisms underlying the response of complex $\mathrm{Mg}$ alloys to cyclic loading may lead to microstructures optimized for maximum fatigue performance under desired loading conditions and overall improvement of mechanical properties.

\section{Acknowledgements}

The authors acknowledge the financial support from the Ministry of Education and Science of Russia through the contract RFMEFI58314X0006. Special thanks go to K.S. Shin (Seoul National University, Korea) for his kind co-operation within this project, stimulating interest and many useful discussions. We also gratefully thank E. Rzevskaya for her skillful assistance with SEM observations of fracture surfaces.

\section{Author Contributions}

All authors have contributed to the study and preparation of the article. E.V. performed the microstructural characterization and tensile tests. M.L. performed the fatigue tests. D.N. and O.S. processed the samples by MIF. M.M. advised for the MIF technique and microstructural observations. A.V. conceived the idea and wrote the paper. All authors have discussed the results, read and approved the final manuscript.

\section{Conflicts of Interest}

The authors declare no conflict of interest.

\section{References}

1. Xiong, Y.; Jiang, Y. Fatigue of ZK60 magnesium alloy under uniaxial loading. Int. J. Fatigue 2014, 64, 74-83.

2. Matsuzuki, M.; Horibe, S. Analysis of fatigue damage process in magnesium alloy AZ31. Mater. Sci. Eng. A 2009, 504, 169-174.

3. Hasegawa, S.; Tsuchida, Y.; Yano, H.; Matsui, M. Evaluation of low cycle fatigue life in AZ31 magnesium alloy. Int. J. Fatigue 2007, 29, 1839-1845.

4. Begum, S.; Chen, D.L.; Xu, S.; Luo, A.A. Low cycle fatigue properties of an extruded AZ31 magnesium alloy. Int. J. Fatigue 2009, 31, 726-735. 
5. Chen, C.; Liu, T.; Lv, C.; Lu, L.; Luo, D. Study on cyclic deformation behavior of extruded Mg-3Al-1Zn alloy. Mater. Sci. Eng. A 2012, 539, 223-229.

6. Lin, X.Z.; Chen, D.L. Strain controlled cyclic deformation behavior of an extruded magnesium alloy. Mater. Sci. Eng. A 2008, 496, 106-113.

7. Lee, S.; Wang, H.; Gharghouri, M. Twinning-detwinning behavior during cyclic deformation of magnesium alloy. Metals 2015, 5, 881-890.

8. Valiev, R.Z.; Estrin, Y.; Horita, Z.; Langdon, T.G.; Zehetbauer, M.J.; Zhu, Y.T. Producing bulk ultrafine-grained materials by severe plastic deformation. JOM 2006, 58, 33-39.

9. Mukai, T.; Yamanoi, M.; Watanabe, H.; Higashi, K. Ductility enhancement in AZ31 magnesium alloy by controlling its grain structure. Scr. Mater. 2001, 45, 89-94.

10. Agnew, S.R.; Mehrotra, P.; Lillo, T.M.; Stoica, G.M.; Liaw, P.K. Texture evolution of five wrought magnesium alloys during route A equal channel angular extrusion: Experiments and simulations. Acta Mater. 2005, 53, 3135-3146.

11. Agnew, S.R.; Horton, J.A.; Lillo, T.M.; Brown, D.W. Enhanced ductility in strongly textured magnesium produced by equal channel angular processing. Scr. Mater. 2004, 50, 377-381.

12. Zúberová, Z.; Kunz, L.; Lamark, T.T.; Estrin, Y.; Janeček, M. Fatigue and tensile behavior of cast, hot-rolled, and severely plastically deformed AZ31 magnesium alloy. Metall. Mat. Trans. A 2007, 38, 1934-1940.

13. Vinogradov, A.; Orlov, D.; Estrin, Y. Improvement of fatigue strength of a $\mathrm{Mg}-\mathrm{Zn}-\mathrm{Zr}$ alloy by integrated extrusion and equal-channel angular pressing. Scr. Mater. 2012, 67, 209-212.

14. Estrin, Y.; Vinogradov, A. Extreme grain refinement by severe plastic deformation: A wealth of challenging science. Acta Mater. 2013, 61, 782-817.

15. Knauer, E.; Freudenberger, J.; Marr, T.; Kauffmann, A.; Schultz, L. Grain refinement and deformation mechanisms in room temperature severe plastic deformed Mg-Az31. Metals 2013, 3, 283-297.

16. Orlov, D.; Raab, G.; Lamark, T.T.; Popov, M.; Estrin, Y. Improvement of mechanical properties of magnesium alloy ZK60 by integrated extrusion and equal channel angular pressing. Acta Mater. 2011, 59, 375-385.

17. Estrin, Y.; Yi, S.B.; Brokmeier, H.G.; Zuberova, Z.; Yoon, S.C.; Kim, H.S.; Hellmig, R.J. Microstructure, texture and mechanical properties of the magnesium alloy AZ31 processed by ecap. Int. J. Mater. Res. 2008, 99, 50-55.

18. Höppel, H.W.; Zhou, Z.M.; Mughrabi, H.; Valiev, R.Z. Microstructural study of the parameters governing coarsening and cyclic softening in fatigued ultrafine-grained copper. Philos. Mag. A 2002, 82, 1781-1794.

19. Höppel, H.W.; Mughrabi, H.; Vinogradov, A. Fatigue Properties of Bulk Nanostructured Materials; Wiley-VCH Verlag GmbH \& Co. KGaA: Weinheim, Germany, 2009; pp. 481-500.

20. Agnew, S.R.; Vinogradov, A.Y.; Hashimoto, S.; Weertman, J.R. Overview of fatigue performance of $\mathrm{Cu}$ processed by severe plastic deformation. J. Electron. Mater. 1999, 28, 1038-1044.

21. Zhu, R.; Wu, Y.J.; Ji, W.Q.; Wang, J.T. Cyclic softening of ultrafine-grained az31 magnesium alloy processed by equal-channel angular pressing. Mater. Lett. 2011, 65, 3593-3596.

22. Nugmanov, D.R.; Sitdikov, O.S.; Markushev, M.V. Microstructure evolution in ma14 magnesium alloy under multi-step isothermal forging. Lett. Mater. 2011, 1, 213-216. 
23. Nugmanov, D.R.; Sitdikov, O.S.; Markushev, M.V. About fine-grain structure forming in bulk magnesium alloy ma14 under multidirectional isothermal forging. Bas. Probl. Mater. Sci. 2012, 9, 230-234.

24. Suresh, S. Fatigue of Materials; Cambridge University Press: London, UK, 1991; p. 617.

25. Estrin, Y.; Vinogradov, A. Fatigue behaviour of light alloys with ultrafine grain structure produced by severe plastic deformation: An overview. Int. J. Fatigue 2010, 32, 898-907.

26. Wu, L.; Stoica, G.M.; Liao, H.H.; Agnew, S.R.; Payzant, E.A.; Wang, G.Y.; Fielden, D.E.; Chen, L.; Liaw, P.K. Fatigue-property enhancement of magnesium alloy, AZ31B, through equal-channel-angular pressing. Metall. Mater. Trans. A 2007, 38, 2283-2289.

27. Dong, S.; Jiang, Y.; Dong, J.; Wang, F.; Ding, W. Cyclic deformation and fatigue of extruded ZK60 magnesium alloy with aging effects. Mater. Sci. Eng. A 2014, 615, 262-272.

28. Yu, Q.; Zhang, J.; Jiang, Y.; Li, Q. An experimental study on cyclic deformation and fatigue of extruded ZK60 magnesium alloy. Int. J. Fatigue 2012, 36, 47-58.

29. Vinogradov, A.; Orlov, D.; Danyuk, A.; Estrin, Y. Deformation mechanisms underlying tension-compression asymmetry in magnesium alloy ZK60 revealed by acoustic emission monitoring. Mater. Sci. Eng. A 2015, 621, 243-251.

30. Vinogradov, A.; Orlov, D.; Danyuk, A.; Estrin, Y. Effect of grain size on the mechanisms of plastic deformation in wrought $\mathrm{Mg}-\mathrm{Zn}-\mathrm{Zr}$ alloy revealed by acoustic emission measurements. Acta Mater. 2013, 61, 2044-2056.

31. Wu, L. Mechanical Behavior and the Role of Deformation Twinning in Wrought Magnesium Alloys Investigated Using Neutron and Synchrotron X-ray Diffraction. Doctoral Dissertation, The University of Tennessee, Knoxville, TN, USA, 2009.

32. Constantinescu, D.M.; Moldovan, P.; Sillekens, W.H.; Sandu, M.; Bojin, D.; Baciu, F.; Apostol, D.A.; Miron, M.C. Static and fatigue properties of magnesium alloys used in automotive industry. Sci. Bull. Automot. Ser. 2009, 19(B), 33-39.

33. Vinogradov, A. Mechanical properties of ultrafine-grained metals: New challenges and perspectives. Adv. Eng. Mater. 2015, doi:10.1002/adem.201500177.

34. Nugmanov, D.R.; Sitdikov, O.S.; Markushev, M.V. Texture and anisotropy of yield strength in multistep isothermally forged $\mathrm{Mg}-5.8 \mathrm{Zn}-0.65 \mathrm{Zr}$ alloy. IOP Conf. Ser. Mater. Sci. Eng. 2015, 82, 012099.

(C) 2015 by the authors; licensee MDPI, Basel, Switzerland. This article is an open access article distributed under the terms and conditions of the Creative Commons Attribution license (http://creativecommons.org/licenses/by/4.0/). 